\title{
Trade Patterns and Welfare
}

\author{
Roberto A. De Santis \\ European Central Bank
}

\author{
Frank Stähler \\ University of Otago
}

\begin{abstract}
By employing a model with international trade costs and imperfect competition, in which a domestic firm serves both the domestic market and the foreign market, we show that intraindustry trade compared to intersectoral trade is globally, but not mutually, welfare improving. When also foreign firms become active, competition strengthens but domestic welfare declines, because domestic consumers have to bear trade costs.

- JEL Classifications: F12, F15

- Key words: Trade, Development, Imperfect competition, Welfare

\section{Introduction}

This paper analyses the global welfare effects of a switch in market regimes with trade. In particular, we show that intraindustry trade is globally but not mutually welfare improving compared to intersecoral trade. We analyse three different market regimes. Under the first regime, a single domestic firm serves both a domestic and a foreign market. Under the second regime, the monopoly is successfully contested by potential domestic rivals such that a domestic oligopoly emerges. Under the third regime, this domestic oligopoly is successfully contested

\footnotetext{
*Corresponding address: Roberto A. De Santis, European Central Bank, Kaiserstrasse 29, D-60311 Frankfurt am Main, Germany, E-mail: roberto.de_santis@ecb.int, Frank Stähler, Department of Economics, University of Otago, PO Box 54, Qunedin, New Zealand, E-mail: fstaehler@business.otago.ac.nz

*The views expressed in this study are those of the authors and do not necessarily reflect those of the European Central Bank. We are grateful to an anonymous referee for useful comments and suggetions. All errors are author's responsibility.

C2005-Center for International Economics, Sejong Institution, All Rights Reserved.
} 
by potential foreign rivals such that an international oligopoly emerges.

The reason why markets undergo these different regimes can be various. One reason could be that a domestic firm has developed a new product, and that this firm gains a temporary monopoly due to patent protection and imitation lags. ${ }^{1}$ Then, this monopoly is contested by local rivals first because they can recruit human capital which is able to imitate the monopoly. Market entry by local rivals will then occur until excess profits are equal to zero. Finally, also the foreign country has acquired the skills to imitate the domestic firms and to host the industry, and both domestic and foreign firms will enter or leave the market until excess profits are zero.

Under the first two regimes, the cross-border trade patterns are of the intersectoral type. Under the third regime, countries engage in intraindustry trade. As we move along the three different regimes, the market structure and welfare in both countries change. However, these effects have either been ignored or downplayed in the literature. The trade models with endogenous market structures and homogeneous commodities have focused upon the impact of intraindustrytrade compared to autarky (Brander, 1981, Brander and Krugman, 1983), or have examined the impact of small policy changes on the equilibrium when intraindustry trade has already taken place (Venables, 1985). However, none of these models can help us understanding the implications on market structure and welfare of intraindustry trade replacing intersectoraltrade. ${ }^{2}$

We begin the analysis by considering the switch from a domestic monopoly to a domestic oligopoly with free entry. The foreign country gains from this switch, but the effect on domestic welfare is ambiguous, because firms can no longer extract rents from the foreign country. We then discuss the effects when the product is manufactured also by foreign firms. The key result of this paper is that intraindustry trade compared to intersectoral trade is globally but not mutually welfar enhancing. In this case, intraindustry trade compared with intersectoral trade results in a welfare gain for the foreign country because more firms are in the market, including foreign firms which do not incur trade costs to serve their own market. The domestic country, however, is worse off because, although the number of active firms increases, foreign firms dump into the home market of domestic

\footnotetext{
${ }^{1}$ We should emphasize that we do not model the process of research and development so that we do not consider the corresponding costs and the incentive to develop a new product.

${ }^{2}$ Brander and Krugman (1983) have shown that intraindustry trade is welfare improving compared to autarky under free entry.
} 
firms. ${ }^{3}$

The paper is organized as follows. Section 2 sets up the model. Section 3 discusses the implications of changes in the market regime on welfare, trade and market structures. Section 4 concludes.

\section{The Model}

As in Brander (1981) and Brander and Krugman (1983), the world consists of two countries, a domestic country $d$ and a foreign country $f$, which have identical tastes. Each country is endowed with a certain amount of a factor of production $L$. In both countries, a good $Y$ is produced by using this input, such that $L^{Y}=Y$, where the superscript denotes the sector in which the factor of production is used. The price of $Y$ equals the return on $L$ and $Y$ is the numeraire of the model. Exporting $Y$ is assumed to raise no trade costs. Additionally, a good $X$ is produced with increasing returns. Consumer behavior in each country is determined by a linear quadratic utility function $U_{i}=U\left(X_{i}, Y_{i}\right)=\alpha X_{i}-0.5 \beta X_{1}^{2}+Y_{i}$, with $\alpha, \beta>0, i \in$ $\{d, f\}$. Given the resource constraint $L_{i}+\sum \pi_{i}=p_{i} X_{i}+Y_{i}, i \in d, f$, where $\sum \pi_{i}$ denotes the oligopolistic industry's aggregate profits, utility maximization yields the inverse income inelastic demand function $p_{i}=\alpha-\beta X_{i}, i \in\{d, f\}$, where $p_{i}$ denotes the price of $X_{i}$ in terms of the numeraire.

As in Venables (1985), each firm faces a fixed setup cost and produces one good, which is traded within the domestic market and exported. The production decisions of firms depend on the fixed setup costs $F$, the domestic marginal cost $c$, and the trade costs $t$ with $\alpha>(c+t)$. Assume that markets are segmented so that each firm maximizes its profit function with respect to both exports, $x_{f}$, and the production for the domestic market, $x_{d}$, and independently chooses the profitmaximizing quantity for each country. Then, the profits of a domestic firm, $\pi$, are

$$
\pi=\left(p_{d}-c\right) x_{d}+\left(p_{f}-c-t\right)^{x} f-F
$$

The definition of profits indicates that exports are at a cost disadvantage if they

\footnotetext{
${ }^{3}$ This result may also explain the efforts made by industrialized countries to restrict imitation by developing countries. The most comprehensive treaty in this field is the Agreement on Trade Related Aspects of Intellectual Property Rights (TRIPS Agreement), which has been signed by WTO members. For the impact of TRIPS on R\&D activities, see Chin and Grossman (1990), Diwan and Rodrik (1991), Taylor (1994) and Zigic (2000).
} 
compete with local production in the foeign country because an exporting firm has to carry trade costs. Under imperfect competition, trade costs will be borne by both consumers and firms, and we will demonstrate that the change in trade costs borne by consumers will determine the welfare changes from regime 2 to regime 3 . Under regimes 1 and 2, the oligopolistic industry is concentrated in the domestic country only. The equilibrium in the commodity market is then given by $X_{d}=N x_{d}$ and $X_{f}=N x_{f}$, where $N$ denotes the number of domestic firms and $X_{d}\left(X_{f}\right)$ represents consumption in the domestic (foreign) country. Since there is no competition by foreign firms, intersectoral trade is profitable if $t<\alpha$-c. The first order conditions for profit maximization and the zero profit conditions yield the equilibrium number of firms in regme $2, N^{*}$, the firm's optimal domestic production, $x_{d}^{*}$, the firm's optimal exports, $x_{f}^{*}$, the domestic equilibrium price, $p_{d}^{*}$ and the foreign equilibrium price, $p_{f}^{*}$ respectively:

$$
\begin{gathered}
N^{*}=\sqrt{\frac{(a-c)^{2}+(\alpha-c-t)^{2}}{\beta F}}-1, \\
x_{d}^{*}=(\alpha-c) /\left[\beta\left(N^{*}+1\right)\right], \quad x_{f}^{*}=(\alpha-c-t) /\left[\beta\left(N^{*}+1\right)\right], \\
p_{d}^{*}=\left(\alpha+c N^{*}\right) /\left(N^{*}+1\right), \quad p_{f}^{*}=\left[\alpha+(c+t) N^{*}\right] /\left(N^{*}+1\right)
\end{gathered}
$$

Expressions (3) and (4) hold also for regime 1, when $N^{*}=1$. It is important to emphasize that the assumption that markets are segmented does not drive the results. The equilibrium values would not change if markets were assumed to be integrated, because arbitrage is profitable only if the price differential between foreign and domestic prices is larger than the trade cost $t$. By using (4), we observe that $p_{f}^{*}-p_{d}^{*}=t N^{*} /\left(N^{*}+1\right)<t$, which implies that arbitrage will never occur for any finite $N^{*}$.

Now assume that also the foreign country can host the industry (regime 3 ). Then, it is profitable to set up firms in the foreign country or to move from the domestic country to the foreign country. ${ }^{4}$ By symmetry we need to consider only the domestic country. The equilibrium in the commodity market is then $X_{d}=X_{f}=$ $0.5 \hat{N}\left(\hat{x}_{d}+\hat{x}_{f}\right)$, where $\hat{N}$ denotes now the total number of active firms in both countries. The equilibrium number of firms, optimal output and price level are

\footnotetext{
${ }^{4}$ Since equilibrium profits are zero under the last two regimes, the model does not need to assume the establishment of foreign firms by foreign agents. The same results occur if domestic firms relocate to the foreign country.
} 
respectively equal to:

$$
\begin{gathered}
\hat{N}=\frac{(\alpha-c)+(\alpha-c-t)}{\sqrt{2 \beta F-t^{2}}}-1, \\
\hat{x}_{d}=(\alpha-c+0.5 \hat{N} t) /(\beta(\hat{N}+1)), \\
\hat{x}_{f}=[\alpha-c-(0.5 \hat{N} t+1) t] /(\beta(\hat{N}+1)), \\
\hat{p}=(\alpha+\hat{N} c+0.5 \hat{N} t) /(\hat{N}+1) .
\end{gathered}
$$

Eq. (5) to (7) require $t^{2}<\beta F$. If oligopolistic firms existed in both countries and $t^{2}>\beta F$, domestic and foreign firms could not compete in the same market. In this case, $F$ were so low that an exporting firm would face too many local competitors which are at a cost advantage and make exports not profitable. Similarly, when firms are active only in the domestic market and $\mathrm{t}>\alpha-\mathrm{c}$, then exports are not profitable. In both of these cases, the number of active firms in autarky, $\bar{N}$, is equal to

$$
\bar{N}=\frac{\alpha-c}{\sqrt{\beta F}}-1 \geq 1
$$

Expression (8) demands that $\bar{N}$ must be equal or greater than one for the existence of the market under autarky. This condition will help us to prove our main finding.

\section{Endogenous Market Structures and Welfare}

The simple model set up in the previous section allows us to study the impact on welfare and the market structure of a change in market regimes. The quasilinear utility function and the zero profit conditions allow us to measure global welfare under regimes 2 and 3 as a sum of the consumer surplus in both countries. ${ }^{5}$ In fact, by using (5), (6) and (7), the global welfare under intraindustry trade, $\hat{W}$, is

$$
\hat{W}=\hat{N}^{2}(\alpha-c)+(\alpha-c-t)^{2} /\left[4 \beta(\hat{N}+1)^{2}\right]
$$

whereas by using (2), (3) and (4), the global welfare under intersectoral trade, $\mathrm{W}^{*}$, can be written as

\footnotetext{
${ }^{5} L$ is omitted in the welfare analysis for simplicity, as it does not play any role when different market regimes are compared.
} 


$$
W^{*}=N^{* 2}\left[(\alpha-c)^{2}+(\alpha-c-t)^{2}\right] /\left[2 \beta\left(N^{*}+1\right)^{2}\right] .
$$

First, let us compare the solutions of regime 1 and regime 2. Proposition 1 summarizesthe effects on welfare.

Proposition 1: Under intersectoral trade, the switch from a monopoly to an oligopoly with free entry increases world welfare, but has an ambiguous impact on domestic welfare.

\section{Proof: See Appendix A.}

If the fixed costs to start up the production process are relatively large, only few firms are able to enter the market. In this case, the rise in the domestic consumer surplus is not sufficient to compensate for the loss in domestic and foreign profits previouly made by the monopolist. Conversely, if fixed costs are relatively low, a larger number of firms will enter the market, equilibrium prices will be closer to marginal costs and domestic welfare will be enhanced. ${ }^{6}$ However, differentiating (10) with respect to the number of active firms shows that the global gains from increased competition are positive regardless of th size of the fixed costs to start the enterprise.

If the foreign country is also able to host the oligopolistic industry, domestic firms may relocate to the foreign country or new firms may enter and be established in the foreign country. The impact on market structure of intraindustry trade replacing intersectoral trade can be studied by comparing (5) and (2). This comparison shows that $N^{*}$ is larger than $\hat{N}$, if $t^{2}+2(\alpha-c)(\alpha-c-t)$ is less than $\beta F$, which is fulfilled only for an $N^{*}$ less than zero. This contradiction proves the following proposition.

Proposition 2: If exports are profitable, the equilibrium number of active firms is larger when the oligopolistic industry is located in both countries.

The positive market structure effect summarized by Proposition 2 does not imply mutual welfare gains, because foreign firms dump into the home market of domestic firms when trade is of the intraindustry type. Competition by foreign firms forces domestic firms to reduce their size, which implies a rise in average

\footnotetext{
${ }^{6}$ From the viewpoint of the domestic country, it would be optimal if a monopolist charged the monopoly price in the foreign market and marginal costs in the domestic market market.
} 
cost to produce the same unit of output. A rise in the average cost at home is welfare declining.

Proposition 3: Intraindustry trade compared to intersectoral trade is globally welfare enhancing, but welfare decreasing for the domestic country and welfare improving for the foreign country.

Proof: The impact on welfare can be studied by computing the impact on prices or aggregate consumption for each country. Let us consider the effect on aggregate foreign consumption. Expressions (3) and (6) imply

$$
\begin{array}{r}
\hat{X}_{f}=\hat{N}(\alpha-c-0.5 t) /[\beta(\hat{N}+1)]>X_{f}^{*}=N^{*}(\alpha-c-t) /[\beta(\hat{N}+1)] \\
\text { since } \hat{N}>N^{*} .
\end{array}
$$

Expression (11) shows that intraindustry trade is welfare increasing for the foreign country. For the domestic country, consider the profits of a domestic firm (1). The comparison of (3) and (6) shows that $\hat{x}_{f}<x_{f}^{*}$, which implies that the net export revenues, $\left(p_{f}-c-t\right) x_{f}$, decline unambiguously for the domestic firm in the presence of foreign rivals. A decrease in net export revenues requires an increase in net domestic revenues, $\left(p_{d}-c\right) x_{d}$, for the zero profit condition to hold. However, from the first order conditions, individual output and the price cost margin are positively related. Thus, $\left(p_{d}-c\right) x_{d}$ can increase only if both the price cost margin and individual output rise. This price increase implies a welfare loss for the domestic consumer. With regard to global welfare, by comparing (9) and (10), $\hat{W}>W^{*}$ if $\hat{N}>\sqrt{2 \beta F /\left(2 \beta F-t^{2}\right)} N^{*}$. Appendix B shows that this inequality holds for any positive $t$.

Intuitively, the foreign country is better off because more firms are in the market, including foreign firms which do not incur the trade costs to serve their own market. However, the opposite effect holds for the domestic country. Despite the positive market structure effect, intraindustry trade is not beneficial for the domestic country because socially wasteful trade costs have to be borne by consumers. This result is similar to that obtained by Venables (1985) and discussed in Propositions 7 and 8 of his paper. 


\section{Concluding Remarks}

This paper has studied the impact of trade on welfare and market structure in a two country setting under three different marke regimes: (i) monopoly in the domestic country only, (ii) oligopoly with free market entry in the domestic country only, and (iii) an international oligopoly with free market entry in both countries. We have shown that the domestic country's welfare does not necessarily increase with free market access at home. However, if foreign firms are active in both markets, domestic welfare declines, despite the increase in the number of competing firms, because domestic consumers have to bear trade costs. This finding may explain why countries hosting an oligopolistic industry are reluctant to allow imitation by other countries even if imitation at home has already taken place. However, any restriction is not the right policy to conduct because we have shown that intraindustry trade compared to intersectoral rade is globally welfare enhancing.

\section{Appendix A}

Proof: By using (10), it is clear that $d W^{*} / d N^{*}>0 .{ }^{7}$ Regarding the indeterminate impact on domestic welfare, we can demonstrate this Proposition by considering the special case of $t=0$. In this case, domestic welfare under intersectoral trade with an endogenous market structure, $W^{d}$, is $W^{*} / 2$. By using (2), $W^{d}$ can be written in a reduced form as follows:

$$
W^{d}=\frac{F}{4}\left[(a-c) \sqrt{\frac{2}{\beta F}}-1\right]^{2} .
$$

The domestic welfare when markets are dominated by a domestic monopolist, $W^{m}$, is the sum of the consumer surplus plus the producer surplus. It can be easily verified that this sum is equal to

$$
W^{m}=\frac{5(\alpha-c)^{2}}{8 \beta}-F \text {. }
$$

Let $\Omega(\mathrm{F}):=W^{m}-W^{d}$ denote the difference between domestic welfare under regime 1 and under regime 2 as a function of the fixed costs. Then, it can easily be shown that $\Omega(F)$ is concave and has a maximum at $\mathrm{F}=2(\alpha-c)^{2} / 25 \beta$. Since $\Omega(F)$ is zero for $F=(\alpha-c)^{2} / 50 \beta$ and since $F$ must be lower than $(\alpha-c)^{2} / 4 \beta$ (see condition

\footnotetext{
${ }^{7}$ Needless to say that foreign welfare will increase with market entry in the domestic country.
} 
(8)), $\Omega$ is positive (negative) in the relevant range if $\mathrm{F}>(<)(\alpha-\mathrm{c})^{2} / 50 \beta$.

\section{Appendix B}

Let us first consider the border case $\mathrm{t}^{2}=\beta F$. Then, by using (2), (5), (9) and (10), intraindustry trade welfare dominates intersectoral trade if

$$
\hat{N} \geq \sqrt{2} N^{*}
$$

Eqs. (2) and (5) allow us to rearrange (14) as follows:

$$
\frac{(\alpha-c)+(\alpha-c-t)}{t}-1 \geq \sqrt{2}\left\lceil\frac{\sqrt{(\alpha-c)^{2}+(\alpha-c-t)^{2}}}{t}-1\right\rceil
$$

which is fulfilled only if $t \leq \alpha-c$. Note that $\hat{W}>W^{*}$ for $t^{2}=\beta F$. In addition, since $\sqrt{\beta F}<\alpha-c, \hat{W}>W^{*}$ for all $t$ larger than $\sqrt{\beta F}^{8}$.

Let us now consider the general case when intraindustry trade occurs. Assume that

$$
t^{2}=\beta F / \gamma \text { with } \gamma>1
$$

Since $\hat{W}=W^{*}$ for $t=0$ (that is, for $\gamma \rightarrow \infty$ ), $\hat{W}>W^{*}$ for $t^{2}=\beta F$, and the welfare functions are twice differentiable with respect to $t$, a necessary condition for a possible welfare dominance of intersectoral trade is that a $\gamma>1$ exists for which $\hat{W}=W^{*}$. If this cannot be found, $W^{*}$ will always be below $\hat{W}$ and Proposition 4 is proved. Insert (16) into (10) and (9). Then, $\hat{W}=W^{*}$ if

$$
(\alpha-c)+(\alpha-c-t)+(\sqrt{2 \gamma}-\sqrt{2 \gamma-1}) t=\sqrt{2 \gamma} \sqrt{(\alpha-c)^{2}(\alpha-c-t)^{2}} .
$$

Rearrange (17) and solve for $t$. Then,

$$
t=\frac{2(\sqrt{2 \gamma}-\sqrt{2 \gamma-1})(\alpha-c)}{\sqrt{2 \gamma(2 \gamma-1)}+\sqrt{2 \gamma}+1-2 \gamma-\sqrt{2 \gamma-1}} .
$$

From (8), $t$ is equal to $(\alpha-\mathrm{c}) /(\sqrt{\gamma}(\bar{N}+1))$. Replace $t$ in (18) and solve for $\bar{N}$

$$
\bar{N}=\frac{\sqrt{2 \gamma-1}(\sqrt{2 \gamma}+2 \sqrt{\gamma}-1)-2 \gamma(1+\sqrt{2})+\sqrt{2 \gamma}+1}{2 \sqrt{\gamma}(2 \gamma-\sqrt{2 \gamma-1})} .
$$

${ }^{8}$ Global welfare cannot increase with trade costs. This can be observed by differentiating (9) and (10) with respect to $t$, and by taking into account that both $\hat{N}$ and $N^{*}$ also decrease with $t$ (see (5) and (2)). 
$\bar{N} \geq 1$ implies that

$$
f(\gamma):=1-2 \gamma+\sqrt{2 \gamma} \sqrt{2 \gamma-1}+(\sqrt{2 \gamma}-\sqrt{2 \gamma-1})(1-4 \sqrt{\gamma}) \geq 0
$$

If the function $\mathrm{f}(\gamma)$ is negative for all $\gamma>1$, the proof is complete. Differentiation of $f(\gamma)$ with respect to $\gamma$ yields

$$
f^{\prime}=\frac{\sqrt{2 \gamma}-\sqrt{2 \gamma-1}}{\sqrt{2 \gamma} \sqrt{2 \gamma-1}}[(1+2 \sqrt{2})(\sqrt{2 \gamma}-\sqrt{2 \gamma-1}-1)] .
$$

For $\mathrm{f}^{\prime}\left(\gamma^{*}\right)=0$ we find that

$$
f^{\prime \prime}\left(\gamma^{*}\right)=\frac{\sqrt{2 \gamma^{*}}-\sqrt{2 \gamma^{*}-1}}{\sqrt{2 \gamma^{*}} \sqrt{2 \gamma^{*}-1}}\left(1+2 \sqrt{\gamma^{*}}\right)\left(\frac{1}{\sqrt{2 \gamma^{*}}}-\frac{1}{\sqrt{2 \gamma^{*}-1}}\right)<0
$$

Hence, $f(\gamma)$ is convex at $\gamma^{*}$ and in the neighborhood of $\gamma^{*}$ so that we may conclude that $f^{\prime}\left(\gamma^{*}\right)=0$ gives a local maximum. Since the welfare functions are twice continuously differentiable with respect to $t, \gamma^{*}$ is the only maximum. Any other $\gamma$ cannot bring about a larger $f$. Solving for the maximum leads to $\gamma^{*}=2.09064$ which implies $f\left(\gamma^{*}\right)=-0.7836$ so that $f(\gamma) \leq-0.7836$. The proof is so complete, because it proves that $f(\gamma)$ is negative for all $\gamma>1$ in contrast with (20).

Received 2 August 2002, Accepted 7 May 2004

\section{References}

Brander, J.A. (1981), Intraindustry trade in identical commodities, Journal of International Economics, 11: 1-14.

Brander, J.A., Krugman, P.R. (1983), A 'reciprocal dumping' model of internationaltrade, Journal of International Economics, 15: 313-323.

Chin, J.C. and G.M. Grossman (1990), Intellectual Property Rights and NorthSouth Trade, in R.W. Jones and A.O. Krueger (eds.), The Political Economy of International Trade. Oxford, Basil Blackwell, 90-107.

Correa, C.M. (1998), Implementing the TRIPS Agreement in the Patent Fields. Option for Developing Countries, The Journal of World Intellectual Property, 1: 75-99.

Diwan, I., Rodrik, D. (1991), Patents, Appropriate Technology, and NorthSouth Trade, Journal of International Economics, 30: 27-47.

Taylor, M.S. (1994), TRIPS, Trade, and Growth, International Economic Review, 35: 361381.

Venables, A.J. (1985), Trade and Trade Policy with Imperfect Competition: The Case of 
Identical Products and Free Entry, Journal of International Economics, 19: 1-19. Verma, S.K. (1998), Exhaustion of Intellectual Property Rights and Free Trade Article 6 of the TRIPS Agreement, International Review of Industrial Property and Copyright Law, 29: 534-567.

Zigic, K. (2000), Strategic Trade Policy, Intellectual Property Rights Protections, and NorthSouth Trade, Journal of Development Economics, 61: 27-60. 